\title{
Coercion, Violation of Privacy and Everyday Difficulties as the Cause of Patient Refusal Treatment in Psychiatric Hospitals in Russia
}

\author{
Natalia K. Rzhevskaya*, Viktor A. Ruzhenkov, Victoria V. Ruzhenkova, Ulyana S. \\ Moskvitina and Marina A. Kolosova
}

\author{
Belgorod State University, Medical Institute, 301015, 85 Pobedy St., Belgorod, Russia
}

\begin{abstract}
Treatment in a psychiatric hospital is accompanied by a restriction of independence, violation of privacy, coercion, which causes displeasure of patients. The aim of the study was to verify the scale of everyday problems, violations of privacy and coercion in a psychiatric hospital to develop recommendations for the organization of a therapeutic environment. The study included 191 patients in a psychiatric hospital. Anonymous questionnaire was used. Statistical processing of the database was carried out by nonparametric methods. The majority of patients $(67 \%)$ estimated the conditions of stay in a psychiatric hospital at 7-10 points (10-point scale), but half of them complained about the need for self-purchase of drugs. A full night's sleep was disturbed by the snoring of others $(56.5 \%)$, an uncomfortable bed $(36.6 \%)$, bright light $(26.2 \%)$. The poor diet was indicated by $45.5 \%$ of patients. Patients indicated coercion by medical staff: retention $(11.5 \%)$, forced administration of drugs $(12 \%)$, coercion to consent to treatment $(22 \%)$, refusal to discharge from hospital $(35.1 \%)$. It was reported that there was a violation of privacy in the toilet $(36.6 \%)$, difficulties to observe the intimate hygiene (16.8\%). These problems caused patients to refuse inpatient treatment if there was the possibility of outpatient treatment $(65.2 \%$ of men and $52.6 \%$ of women). Despite the low level of claims of patients to living conditions, it is important to respect their rights in psychiatric hospitals to privacy, creating a comfortable living space, the organization of differentiated methods of observation by medical staff.
\end{abstract}

Keywords: Mental disorders, psychiatric hospital, coercion, violation of privacy, domestic problems, refusal of hospitalization.

\section{INTRODUCTION}

The biopsychosocial concept of mental health care is based on the protection of the patient's whole personality, full social adaptation and improvement of the quality of life. This is impossible without respect for fundamental human rights to life, freedom and dignity (Kerbage et al., 2016). However, psychiatric patients have a wide range of limitations (Barnicot et al., 2017). The majority $(80 \%)$ of patients noted insufficient independence, lack of freedom of action during their stay in the ward. They negatively responded about the all-day observation by medical staff (Woodward et al., 2017). A quarter $(25 \%)$ of patients reported intimate disorders and the presence of other patients or medical staff during hygiene procedures (Kruchinin, 2015). Some patients pointed to the impossibility of sexual intimacy (Quinn \& Happell, 2016). Communication of patients with relatives and telephone conversations in many psychiatric hospitals take place in the presence of medical staff (Minoletti et al., 2015). Often the use of the phone is completely prohibited.

The majority $(80 \%)$ of patients in psychiatric hospitals characterized their stay in a psychiatric

*Address correspondence to this author at the Belgorod State University, Medical Institute, 301015, 85 Pobedy St., Belgorod, Russia; Tel: +7 (8617) 2213-27, 22-14-03; Fax: +7 (8617) 22-13-27; E-mail: sun.vandre@gmail.com hospital as "sleepy idleness". They pointed to the inability to use the library, the lack of physical therapy, psychotherapy, rare short walks (Hopkins et al., 2009). Relevant were the difficulties when you were informed about medical care and discussion with the physician treatment plan. Often there were obstacles in getting acquainted with their medical documentation (Wyder et al., 2016). Lack of medical staff and increased workload in psychiatric hospitals leads to unethical, dismissive attitude of medical staff to patients, prevents the formation of a positive therapeutic environment (Eren, 2014). In this regard, there is a low public satisfaction with outcomes of mental health care (Ruzhenkov et al., 2014; Ruzhenkov \& Shyerbak, 2006; Shvets \& Khamskaya, 2019).

\section{AIM}

The aim of the study was to verify the scale of domestic problems, violations of privacy and coercion in a psychiatric hospital of Russia for the adult patients, their impact on the attitude to therapy to develop recommendations for the organization of a favorable therapeutic environment.

\section{MATERIAL AND METHODS}

An anonymous survey (questionnaire) of 191 patients was conducted: 65 male and 126 female 
patients aged 16-76 $(46 \pm 14.5)$ years who were treated in a psychiatric hospital. The main methods of research were medical and sociological (questioning by means of the author's questionnaire containing social and demographic and clinical information, questions of satisfaction with quality of the received medical services, existence and types of coercion). Domestic problems and violations of privacy were verified with the help of "Methods of studying domestic problems and violations of privacy in a psychiatric hospital" (Rzhevskaya \& Ruzhenkov, 2017).

Statistical processing of the database (descriptive statistics, the $x^{2}$ with the Yates correction for contingency tables $2 \times 2$ ) was carried out with the power of the package of applied statistical programs Statistica 6.0 .

\section{RESULTS AND DISCUSSION}

Among the examined patients, persons with secondary special education prevailed: $50.8 \%$ - men and $42.1 \%$ - women. A third of the respondents had a higher education $(30.4 \%)$, and more often among female subjects $-37.3 \%\left(x^{2}=7.486, p=0.007\right)$ than among men - $16.9 \%$. Thus, the level of education of respondents was sufficient for the correct assessment of living conditions and ethical aspects of the relationship with health workers.
The duration of the mental disorder before the examination period was from 1 to $61(11 \pm 8.8)$ years. The number of hospitalizations in a psychiatric hospital is presented in Table $\mathbf{1}$.

The frequency of hospitalizations did not differ between males and females. One third $(34.8 \%)$ of men and more than half $(52.6 \%)$ of women were hospitalized on the initiative of spouses or family members. More than half of the patients (53.4\%) were previously treated in a psychiatric hospital. At the same time $65.2 \%$ of men and $34.8 \%$ of women noted that they had also been hospitalized at the insistence of spouses and parents $\left(x^{2}=5.11, p=0.024\right)$.

The clinical structure of mental disorders in the examined patients is presented in Table 2.

Organic mental disorders were represented by organic mood disorders, organic anxiety disorders, organic personality and behavior disorders and were observed in $41.5 \%$ of males and only $22.2 \%$ of females $\left(x^{2}=6.889, p=0.01\right)$. Schizophrenia, schizotyp $-22.2 \%$ ic and delusional disorders were more common in men $(43.1 \%)$ than in women $\left(x^{2}=8.012, p=0.006\right)$.

Affective disorders were represented by moderate to severe depressive episodes, recurrent depressive and bipolar affective disorders.

Table 1: Number of Hospitalizations of Patients in a Psychiatric Hospital

\begin{tabular}{|c|c|c|c|c|c|c|c|}
\hline \multirow{2}{*}{ № } & \multirow{2}{*}{ Number of hospitalizations } & \multicolumn{2}{|c|}{ Male } & \multicolumn{2}{|c|}{ Female } & \multicolumn{2}{|c|}{ Total } \\
\hline & & $\mathbf{n}$ & $\%$ & $\mathbf{n}$ & $\%$ & $\mathbf{n}$ & $\%$ \\
\hline 1 & First hospitalization & 12 & 18.5 & 33 & 26.2 & 45 & 23.6 \\
\hline 2 & The second hospitalization & 14 & 21.5 & 30 & 23.8 & 44 & 23.0 \\
\hline 3 & Multiple hospitalizations & 39 & 60 & 63 & 50 & 102 & 53.4 \\
\hline & Total & 65 & 100 & 126 & 100 & 191 & 100 \\
\hline
\end{tabular}

Table 2: Clinical Structure of Mental Disorders (ICD-10)

\begin{tabular}{|c|c|c|c|c|c|c|c|}
\hline \multirow{2}{*}{ № } & \multirow{2}{*}{ Nosological categories } & \multicolumn{2}{|c|}{ Male } & \multicolumn{2}{|c|}{ Female } & \multicolumn{2}{|c|}{ Total } \\
\hline & & $\mathbf{n}$ & $\%$ & $\mathbf{n}$ & $\%$ & $\mathbf{n}$ & $\%$ \\
\hline 1 & Organic, including symptomatic, mental disorders & 27 & 41.5 & 28 & 22.2 & 55 & 28.8 \\
\hline 2 & Schizophrenia, schizotypal and delusional disorders & 28 & 43.1 & 28 & 22.2 & 56 & 29.3 \\
\hline 3 & Mood (affective) disorders & 4 & 6.2 & 48 & 38.1 & 52 & 27.2 \\
\hline 4 & Neurotic, stress-related and somatoform disorders & 3 & 4.6 & 18 & 14.3 & 21 & 11.0 \\
\hline 5 & Disorders of adult personality and behaviour & 3 & 4.6 & 4 & 3.2 & 7 & 3.7 \\
\hline & Total & 65 & 100 & 126 & 100 & 191 & 100 \\
\hline
\end{tabular}


Neurotic, stress-related and somatoform disorders were manifested in the form of mixed anxietydepressive reactions, hypochondriac and dissociative disorders and were found in $11 \%$ of patients. Disorders of personality and behavior in adulthood are diagnosed equally often in males and females.

The majority of patients $-60 \%$ of males and $65.9 \%$ of females were sufficiently aware of their diagnosis.

A study of patients assessment of the comfort of a psychiatric hospital on a 10 point scale showed that $37.7 \%$ of patients gave an assessment of $9-10$ points, $29.3 \%$ of patients $-7-8$ points, $33 \%$ of patients of both sexes -6 or less points. This indicates a low level of claims in persons suffering from mental disorders who are being treated in a psychiatric hospital. They have a habit and adaptation to cramped and uncomfortable conditions, which is associated with both negative symptoms and a low standard of living (in terms of living conditions).

The study of medical problems and problems of domestic amenities, privacy violations in a psychiatric hospital, revealed the inconveniences most often faced by patients in psychiatric hospitals.

The study of medical problems showed that due to the lack of drug provision $50.3 \%$ of patients had to buy their own drugs (as psychotropic $-42.9 \%$, and for the treatment of somatic pathology $-35.1 \%$ ). $42.9 \%$ of women $\left(x^{2}=8.8594 ; p=0.0038 ; O R=3.095 \%\right.$; $C l=1.4-$ 6.4 ) and only $20 \%$ of men indicated a drug deficiency. The lack of drugs - correctors of extrapyramidal symptoms, led to difficulty in life $46.1 \%$ of patients due to side effects of neuroleptics, while in females more often $\quad-\quad 51.6 \% \quad\left(x^{2}=3.9026 ; \quad p=0.0483 ; \quad O R=1.9\right.$ $95 \% ; \mathrm{Cl}=1.0-3.8)$, than male $-35.4 \%$.

The study of everyday problems of patients in a psychiatric hospital showed that more than a third of patients experienced discomfort from the feeling of round-the-clock control by medical staff.

Snoring roommates interfere with restful sleep the majority of patients $(56.5 \%)$, in second place uncomfortable to sleep in a bed (36.6\%). Discomfort created noise and conversations in the ward $(32.5 \%)$, low temperature in the wards $(26.7 \%)$. Constantly switched on a bright light in the wards of the delivered inconveniences of $26.2 \%$ of the patients. About a quarter of women $(22.2 \%)$ noted that it is impossible to sleep in the offices at a convenient time. A slightly smaller number of patients noted the inability to organize their personal space, to receive money deposited, difficulties in receiving guests and using household appliances.

Characteristics of the problems of catering and it is presented in Table 3.

As can be seen from the table, in general, the quality of food and eating problems caused discontent in almost half of the patients. Poor monotonous menu was noted by $45.5 \%$ of patients, $24.6 \%$ of patients complained about the poor quality of food. At the same time, $26.2 \%$ of patients noted difficulties in using the buffet, the inability to purchase the desired products and eat at any time (21.5\%). Difficulties associated with the storage of their products, experienced $15.7 \%$ of patients. $36.1 \%$ and $33.5 \%$ of patients respectively indicated the impossibility to brew tea or coffee at any convenient time. The prohibition to drink alcohol while

Table 3: Problems of Organization and Quality of Food in a Psychiatric Hospital

\begin{tabular}{|c|c|c|c|c|c|c|c|}
\hline \multirow{2}{*}{ № } & \multirow{2}{*}{ Nutritional problem } & \multicolumn{2}{|c|}{ Male } & \multicolumn{2}{|c|}{ Female } & \multicolumn{2}{|c|}{ Total } \\
\hline & & $\mathrm{n}$ & $\%$ & $\mathbf{n}$ & $\%$ & $\mathbf{n}$ & $\%$ \\
\hline 1 & Limited menu & 24 & 36.9 & 63 & 50.0 & 87 & 45.5 \\
\hline 2 & Rare meals & 8 & 12.3 & 14 & 11.1 & 22 & 11.5 \\
\hline 3 & Difficulties in storing your own products & 10 & 15.4 & 20 & 15.9 & 30 & 15.7 \\
\hline 4 & Inability to eat at any time & 13 & 20.0 & 28 & 22.2 & 41 & 21.5 \\
\hline 5 & Inability To drink alcoholic beverages & 12 & 18.5 & 16 & 12.7 & 28 & 14.7 \\
\hline 6 & Difficulties to use the buffet to purchase the desired products & 14 & 21.5 & 36 & 28.6 & 50 & 26.2 \\
\hline 7 & Inability to make coffee & 22 & 33.8 & 42 & 33.3 & 64 & 33.5 \\
\hline 8 & Inability to make tea & 24 & 36.9 & 45 & 35.7 & 69 & 36.1 \\
\hline 9 & Poor quality food & 17 & 26.2 & 30 & 23.8 & 47 & 24.6 \\
\hline
\end{tabular}


Table 4: Physical Restraint and Isolation of Patients during Treatment in a Psychiatric Hospital

\begin{tabular}{|c|c|c|c|c|c|c|c|}
\hline \multirow{2}{*}{ № } & \multirow{2}{*}{ Physical restraint } & \multicolumn{2}{|c|}{ Male } & \multicolumn{2}{|c|}{ Female } & \multicolumn{2}{|c|}{ Total } \\
\hline & & $\mathbf{n}$ & $\%$ & $\mathbf{n}$ & $\%$ & $\mathbf{n}$ & $\%$ \\
\hline 1 & Retention by medical staff & 7 & 10.8 & 15 & 11.9 & 22 & 11.5 \\
\hline 2 & Forced administration of drugs & 5 & 7.7 & 18 & 14.3 & 23 & 12.0 \\
\hline 3 & Fixation to the bed with wide bandages & 10 & 15.4 & 20 & 15.9 & 30 & 15.7 \\
\hline 4 & Fixation to the bed sheets & 1 & 1.5 & 13 & 10.3 & 14 & 7.3 \\
\hline 5 & Fixation to the bed with straps & 6 & 9.2 & 18 & 14.3 & 24 & 12.6 \\
\hline 6 & Isolation in a separate room & 3 & 4.6 & 2 & 1.6 & 5 & 2.6 \\
\hline 7 & Accommodation on a bed in the hall of the department near the nurses ' station & 6 & 9.2 & 20 & 15.9 & 26 & 13.6 \\
\hline
\end{tabular}

in hospital caused discontent of $14.7 \%$ of men and women.

Verification of the problems of ensuring the personal safety of patients in a psychiatric hospital showed that the most frequent threat to safety $(26.2 \%)$ was aggression from other patients. In second place disrespectful and rude attitude, insults from the nurses.

The characteristics of the most common forms of direct coercion in a psychiatric hospital are presented in Table 4.

Various forms of direct coercion by medical staff were noted by about $20 \%$ of the persons participating in the survey. As can be seen from table 7, mainly physical restraint in a psychiatric hospital was applied in the form of fixation of the patient to the bed with wide bandages or belts $-15.7 \%$ and $12.6 \%$, respectively. Patients also reported being held by medical staff (11.5 per cent) and forcible administration of drugs without their consent (12 per cent). Another common form of violation of privacy and coercion was the placement of the patient's bed in the hall in front of the nurses' station for constant monitoring (13.6\%).

Rehabilitation for me over the last 50 years has been a personal roundabout, jumping on and off over the years. As a patient representative locally, regionally and nationally it is now my responsibility as part of the national team to try and express the need, not only for patients, but for our whole NHS system to look in a different way around this important subject. The cases of physical restraint observed by patients and a comparison of their frequency with the frequency indicated in medical documents indicate their more frequent use without indication in medical documentation. In these cases, the decision to use physical restraint was made by the nurses on their own, without the guidance of a psychiatrist. This is due to insufficient monitoring by the head of the department and the senior nurse over the work of medical staff.

The most frequent forms of indirect coercion in a psychiatric hospital were: coercion to sign the consent form for hospitalization (22\%) and refusal to discharge from the hospital $(35.1 \%)$, involvement in the cleaning of the department, unloading of goods (24.6\%).

More than a third of patients $(36.1 \%)$ complained of low physical activity, inability to physical activity $(18.8 \%)$, lack of conditions for morning exercise (15.7\%). Important for patients were the problems of leisure: the inability to participate in games and entertainment $(16.8 \%)$, difficulties in watching TV shows of interest (27.2\%). Insufficient number of outdoor walks was noted by $20.9 \%$ of patients, and $16.2 \%$ indicated difficulties in meeting with relatives.

The characteristics of the most common problems arising from personal hygiene in a psychiatric hospital are presented in Table $\mathbf{5}$.

More than a third of patients of both sexes noted the problems of privacy in the implementation of personal hygiene. The most frequent were: the presence of strangers in the toilet $(36.6 \%)$, the toilet door without a lock $(38.2 \%)$. The inability to take a shower with the usual frequency was indicated by $31.4 \%$ of patients, and $16.8 \%$ - noted the difficulties to observe intimate hygiene and the lack of conditions for quality care of their appearance. In addition, the impossibility of sexual contact is relevant for $16.2 \%$.

These problems led to the fact that the majority of patients - $65.2 \%$ male and $52.6 \%$ female, would refuse treatment in the hospital, if it was possible to treat outpatient. 
Table 5: Problems of Patients ' Personal Hygiene in a Psychiatric Hospital

\begin{tabular}{|c|c|c|c|c|c|c|c|}
\hline \multirow{2}{*}{ № } & \multirow{2}{*}{ Types of problems } & \multicolumn{2}{|c|}{ Male } & \multicolumn{2}{|c|}{ Female } & \multicolumn{2}{|c|}{ Total } \\
\hline & & $\mathbf{n}$ & $\%$ & $\mathbf{n}$ & $\%$ & $\mathbf{n}$ & $\%$ \\
\hline 1 & Inability to wash and shower with the usual frequency & 18 & 27.7 & 42 & 33.3 & 60 & 31.4 \\
\hline 2 & Strangers in the toilet when sending physiological needs & 23 & 35.4 & 47 & 37.3 & 70 & 36.6 \\
\hline 3 & The impossibility of intimate encounters & 11 & 16.9 & 20 & 15.9 & 31 & 16.2 \\
\hline 4 & The impossibility of quality care for their appearance & 9 & 13.8 & 26 & 20.6 & 35 & 18.3 \\
\hline 5 & Failure to adhere to personal hygiene & 11 & 16.9 & 21 & 16.7 & 32 & 16.8 \\
\hline 6 & Bathroom without a lock & 20 & 30.8 & 53 & 42.1 & 73 & 38.2 \\
\hline
\end{tabular}

\section{CONCLUSION}

The majority of patients $(67 \%)$ evaluated the conditions of stay in a psychiatric hospital at 7-10 points (about a 10-point scale) and only a third (33\%) at 6 or less points. Half $(50.3 \%)$ of the patients indicated the need for self-medication. The lack of drugs - correctors of extrapyramidal symptoms, led to difficulty in life $46.1 \%$ of patients due to side effects of neuroleptics. The majority of patients were disturbed by snoring of other patients (56.5\%), uncomfortable bed $(36.6 \%)$. Discomfort in the wards created noise and loud conversations (32.5\%), low temperature $(26.7 \%)$, constantly on light $(26.2 \%)$.

On the limited menu indicated that $45.5 \%$ of the patients and $24.6 \%$ for low quality food. The fourth part $(26.2 \%)$ of patients noted difficulties in using the buffet.

Various forms of direct coercion by medical staff were noted by about $20 \%$ of patients: retention by medical staff $(11.5 \%)$, forced administration of drugs $(12 \%)$. In addition, there were forced signatures in the voluntary consent to hospitalization $(22 \%)$, refusal to discharge from the hospital (35.1\%), involvement in cleaning in the department and the walking yard, unloading and loading operations (24.6\%).

A significant proportion of patients $(36.6 \%)$ indicated a violation of intimacy - the presence of other patients or medical staff in the toilet, not closing the toilet door $(38.2 \%)$. The inability to take a shower with the usual frequency was indicated by $31.4 \%$ of patients, and $16.8 \%$ - noted the difficulties to observe intimate hygiene and the lack of conditions for quality care of their appearance. In addition, the impossibility of sexual contact is relevant for $16.2 \%$.

The mode of the psychiatric hospital and the organization of the therapeutic environment are significantly different from other medical organizations, which causes fair complaints from patients. In a psychiatric hospital, patients are faced with problems of a legal nature, organization of treatment, everyday problems, interpersonal relationships with other patients, ethical aspects of interaction with medical staff. Respecting the right to privacy of patients in psychiatric hospitals requires ergonomic restructuring of the unit's living space and a differentiated, clinically sound monitoring approach by medical staff.

\section{REFERENCES}

Kerbage, H., El Chammay, R., \& Richa, S. (2016). Mental Health Legislation in Lebanon: Nonconformity to international standards and clinical dilemmas in psychiatric practice. International journal of law and psychiatry, 44, 48-53. https://doi.org/10.1016/j.ijlp.2015.08.031

Barnicot, K., Insua-Summerhayes, B., Plummer, E., Hart, A., Barker C., \& Priebe, S. (2017). Staff and patient experiences of decision-making about continuous observation in psychiatric hospitals. Social psychiatry and psychiatric epidemiology, 52(4), 473-483. https://doi.org/10.1007/s00127-017-1338-4

Woodward, S., Berry, K., \& Bucci, S. (2017). A systematic review of factors associated with service user satisfaction with psychiatric inpatient services. Journal of psychiatric research, 92, 81-93.

https://doi.org/10.1016/j.jpsychires.2017.03.020

Kruchinin, Y.S. (2015). Special report of the Commissioner for Human Rights in the Chuvash Republic "On the observance of the rights of citizens held in psychiatric hospitals and psycho-neurological boarding schools of the Chuvash Republic". Cheboksary, 81 (in Russian).

Quinn, C., \& Happell, B. (2016). Supporting the sexual intimacy needs of patients in a longer stay inpatient forensic setting. Perspectives in psychiatric care, 52(4), 239-247. https://doi.org/10.1111/ppc.12123

Minoletti, A., Toro, O., Alvarado, R., Carniglia, C., Guajardo, A., \& Rayo, X. (2015). A survey about quality of care and user $s^{\prime}$ rights in Chilean psychiatric services. Revista médica de Chile, 143(12), 1585-1592. https://doi.org/10.4067/S0034-98872015001200012

Hopkins, J. E., Loeb, S. J., \& Fick, D. M. (2009). Beyond satisfaction, what service users expect of inpatient mental health care: a literature review. Journal of Psychiatric and Mental Health Nursing, 16(10), 927-937. https://doi.org/10.1111/j.1365-2850.2009.01501.x

Wyder, M., Bland, R., \& Crompton, D. (2016). The importance of safety, agency and control during involuntary mental health admissions. Journal of Mental Health, 25(4), 338-342. https://doi.org/10.3109/09638237.2015.1124388 
Eren, N. (2014). Nurses' attitudes toward ethical issues in psychiatric inpatient settings. Nursing Ethics, 21(3), 359-373. https://doi.org/10.1177/0969733013500161

Ruzhenkov, V. A., Minakova, J. S., Ruzhenkova, V. V., \& Moskvitina, U. S. (2014). Factors of social maladjustment of the patients suffering from schizophrenia who have been declared legally incapable in terms of psychopharmacotherapy and rehabilitation. Research Journal of Pharmaceutical, Biological and Chemical Sciences, 5(6), 1384-1388.

Ruzhenkov, V.A., \& Shyerbak, N.A. (2006). The problems of nonvoluntary hospitalization and treatment of patients suffering from schizophrenia. Advances in current natural sciences, 6 , $12-15$.
Shvets, K.N., Khamskaya, I.S. (2019). Factors of social disadaptation of patients with schizophrenia and approaches to psychosocial therapy and rehabilitation (review). Research Results in Biomedicine, 5(2), 72-85 (In Russian). https://doi.org/10.18413/2658-6533-2019-5-2-0-8

Rzhevskaya, N.K., \& Ruzhenkov, V.A. (2017). Methods of study of everyday problems and violation of privacy in a psychiatric hospital. The Journal of scientific articles "Health and Education Millennium", 19(12), 213-217 (in Russian). https://doi.org/10.26787/nydha-2226-7425-2017-19-12-213$\underline{217}$

Received on 04-08-2020

DOI: https://doi.org/10.6000/1929-4409.2020.09.102

(c) 2020 Rzhevskaya et al.; Licensee Lifescience Global.

This is an open access article licensed under the terms of the Creative Commons Attribution Non-Commercial License (http://creativecommons.org/licenses/by-nc/3.0/) which permits unrestricted, non-commercial use, distribution and reproduction in any medium, provided the work is properly cited. 